\title{
The Effect of M-Webquest on Students'Achievement in Reading Comprehension and Self-Learning
}

\author{
Hadriana \\ Faculty Of Education, University Of Riau Indonesia
}

\begin{abstract}
Doi:10.5901/jesr.2015.v5n3p301
\end{abstract}
\section{Abstract}

This is a quasi-experiment to determine the effect of M-Webquest on students' achievement in reading comprehension and self-learning of the English Language subject. 260 students were involved in this study, 130 students were treated in the treatment group and another 130 students were put in the control group. The data was collected by using a questionnaire and a set of test paper was used to test students' reading comprehension. Results of this study has found that there is a significant difference of students achievement in the English Language reading comprehension and self-learning based on the teaching method. The collected data showed a significant difference of students' achievement in reading comprehension based on students' ability. The Pearson Correlation analysis was done and showed a significant relation between self-learning and students' achievement in reading comprehension. The implication of the study on the use of M-WebQuest would definitely help teachers in their teaching and learning process to improve students' achievement in the English language subject particularly in reading comprehension.

Keyword: M-Webquest, achievement in reading comprehension, self-learning

\section{Introduction}

Language is one of the influential factors to determine one's success in learning about oneself, his culture and others as well. Knowing a language is beneficial for students to use their analytical and imaginative abilities to deliver ideas, feelings and to be involved with the society successfully. Language competency would enable one to communicate with other people to voice out his feeling, needs, opinions, experience, thinking, and knowledge, as well as to acquire new knowledge, to get information, and to understand other people verbally or in writing (Raminah Haji Sabran, 1993).

According to Richards (2009), technology helps to accelerate the process of learning a language. Learning English language with the help of a computer would help students to improve their achievement in the language. Hence, technology should be used in the process of learning the English Language subject, as it helps to improve students' achievement in the subject. Thus, teachers are encouraged to use technology as a teaching aid or as one of the teaching methods in the class.

Listening, speaking, reading and writing are the basic skills of learning the English Language subject. Listening is the first skill needed to be acquired before other skills. Children learn to listen first before they can speak, then they can read and after that they know how to write (Asmah Haji Omar, 2004).

The four language skills can be divided into two types of communication skills. Listening and reading are skills to receive communication, whereas speaking and writing are skills to send communication. Listening and speaking skills need audio-oral media, whereas writing and reading skills can use visual graphics as the teaching media (Chew Fong Peng \& Abdul Jalil Othyman 2008). Teachers commonly use various activities in and outside the classroom to help students prepare themselves for the national public examination. In addition, the schools provide several programs to improve students' ability in reading and listening.

Generally, students' competency in the English language is still poor. Even though English language subject is compulsory for all students since lower primary schools, but most of secondary school students are having difficulties to speak the language fluently (Noerdin Soemantri, 2003). It is very important for students to acquire reading skill from the early stage of this education. Hence, reading habit should be inculcated in order to build a strong foundation for reading ability (Azizah Zain 2010).

Rina Febritasari (2010) and Sinur Vera Afriana (2012) have found that some students have difficulty to answer reading comprehension questions because they have very limited English vocabulary. The ability to understand texts is very important in learning, hence when one has difficulty in reading the text, he will not able to comprehend the meaning 
of the text (Rasinski, 2006).

The problem may cause by lack of reading activities especially to strengthen professional and develop character. Apart from that, there is not enough research on reading culture and also less attention on reading strategies (Yahya Othman \& Wan Mat Sulaiman 2011). The problem is rooted from not enough reading exercises to inculcate reading strategies. The common exercises are reading comprehension, finding the main ideas, finding meanings of words and distinguishing between the main points and supporting details. Sadly, most students were confused in responding to the exercises (Sinur Vera Afriana 2012).

Some researchers have identified that comprehension problem is related to the reader's reading habit. Lack of encouragement from family and not enough interesting books are the major factors. A child will be illiterate and unable to read when he cannot meet the expectation of his parents or teachers (Walker, 1992). Due to that, home education is also important. It is parents' responsibility to educate their children and to nurture them before they go to school. It is worthy to note that most children will be left behind if they cannot read at the expected stage.

A good teacher will always try the best to help his students in their study. A teacher can create a communicative and students-centred learning condition, in order to help students improve their achievement in understanding English reading materials. Student-centred learning condition encourages active participation and interaction among students. A systematic and harmonious learning condition is one of the important factors which contribute to successful teaching and learning process. It can also help students to improve their achievement in the English Language subject. In this context, Norashikin Arif and Zuhaidi Mukrim (2005) have stated that it is important for teachers to create an effective teaching condition with systematic computer assisted efforts to increase students' achievement in the English language subject.

Web sites can be self-explored by users as a support material for self-directed learning. On the other hand, it can help poor students as remedial activites to improve their understanding (Azemi 1997). Educational web sites are resources for teachers to plan their teaching. Other than textbooks, teachers can also get ideas from e-books and eresources from the web sites. Hence, teachers have to be ICT literate and put their trust on technology to encourage and upgrade their teaching as well as students' learning experience (Rosnaini Mahmud and Mohd Arif Hj. Ismail 2010).

\section{Learning with WebQuest}

One of the web-based learning models to be used in the classroom is the WebQuest (Norazah Mohd Nordin \& Ngau Chai Hong 2009). The WebQuest model was designed by Dodge in 1995 and then it was further developed by his colleague named March in 1998. According to Dodge, WebQuest is an investigation oriented activity where half or all of the information needed by students come from the internet. WebQuest enables students to explore knowledge virtually and to access lots of information from various websites without being in the classroom. Using WebQuest requires teachers to be a learning planner, guider and facilitator (Simon 2005). A well planned WebQuest should have several components: Introduction, Task, Process, Resources, Assessment and Conclusion. According to Norazah Mohd Nordin and Ngau Chai Hong (2009), WebQuest is a teaching and learning aid which helps students to understand lessons easily.

Learning with the WebQuest has been introduced for quiet sometimes and can be used for various fields of knowledge at all levels of education from primary schools to the university. A research conducted by Wagman (2005) has proven that learning with WebQuest can improve students' motivation, self-effectiveness and self-learning. In addition, WebQuest enables students to independently discover basic knowledge, personal ability, cooperation, critical thinking and strategies for problem solving. Chuo (2007) conducted a study on 54 college students in Taiwan to investigate the use of WebQuest to teach language and its effect on students' ability to write in the English Language. The study found that the students who used WebQuest had better writing performance than those who learned writing conventionally.

\section{Achievement in English Language reading comprehension}

English language is a foreign language taught in the Indonesian secondary schools. Reading is one of the language skills and students' achievement in the subject is tested and evaluated in every single semester to determine students' academic performance. There are many ways to assess students' academic achievement, and one of those is assessment done by the subject teacher in the classroom. The objectives of students' assessment are to determine their achievement and also to improve the achievement if necessary (Ministry of Education and culture, Republic of Indonesia 
2013).

Assessment is done to measure the aspects of students' cognitive, affective and psychomotor achievement. Assessment is also referred to the grade achieved by students in a test or examination (Sahin 2011). However, there is also a non-test kind of assessment where students' achievement is determined during the teaching and learning session (Yuzar Muhammad 2006). In the context of this study, students' achievement in English language reading comprehension is referred to the grade achieved by students in the reading comprehension achievement test given by the subject teacher.

\section{Self-learning}

Self-learning is one of learning styles or learning strategies. It is actually a learning style adopted by a learner to learn independently (Macdougall 2008). An independent student would be able to manage his own learning and is able to shield himself from external influences. In this study, self-learning is referred to a student's ability to motivate himself to learn and develop his own knowledge, to make decision, to manage changes, to achieve his own needs, to solve his own problems, to negotiate with others and also to choose the best style to learn.

According to Little (2000), self-learning does not only mean learning without teachers, however in the context of classroom teaching, even if the teacher is promoting self-learning, the students are still guided about the best thing that they should do. Self-learning is not a simple choice for students to choose their own teaching method but students are actually taught to determine the best option for them to manage their own learning activities. Self-learners are students who independently plan, manage and evaluate their own learning. Macdougall (2008) defined self-learning as a type of learning for students to chart their own way and reduce their dependence on teachers.

\section{Research objectives}

This research is conducted as a quasi-experiment to determine the effect of M-WQ teaching on students' achievement in the English language reading comprehension and also on students' ability for self-learning. Respondents are students from several secondary schools in Pekanbaru, Riau, Indonesia. This is also a comparative study on students' achievement and self-learning by using the M-WQ as an intervention for the students in the treatment group and conventional learning for students in the control group. The comparative study is done based on learning methods and students' ability. In addition, this research also determines the relationship between self-learning and students' achievement in the English language reading comprehension.

\section{Methodology}

260 secondary school students were involved as the respondents of this study. 130 students were then treated with the M-WQ learning method in the treatment group, while another 130 students were put in the control group who learned English Language subject traditionally. The study was designed as the quasi-experiment of non-equivalent pre-test and post-test control group design. Data was analysed from students achievement in reading comprehension test which had 40 reading comprehension questions. A questionnaire on self-learning was also used as the research instrument. The question paper consisted of 22 items of self-learning. A pilot study was conducted on 30 secondary school students to determine the validity, reliability, discrimination index and level of difficulties of each item in the questionnaire. Results of the pilot study showed the level of difficulties of comprehension questions was moderate with the difficulty index between $36.36 \%$ to $66.67 \%$. This showed the difficulty of each question was balanced and almost perfect to test students' achievement. Karno To (1996) has stated that the best value of difficulty index of items is average with the values between $31 \%$ to $70 \%$. Whereas, the value of Discrimation Index for each item of the comprehension questions was at the range of $37.5 \%$ to $87.50 \%$. This shows that the discrimination index of each item in the reading comprehension questions was at a good level. The Alpha cronbach value for the reading comprehension questions was 0.82 , whereas the reliability index for the self-learning aspect was strong with the Alpha Cronbach value of 0.902 


\section{Findings}

\subsection{Comparison of students achievement in the English Language reading comprehension based on teaching methods (between students who used the M-WebQuest and students who learned conventionally)}

The two-way Anova analysis was done to identify any significant difference in reading comprehension achievement between students who used the M-WebQuest and students who learned conventionally.

Table 1. Mean and standard deviation of reading comprehension achievement based on teaching method, between students who used the M-WebQuest and students who learned conventionally

\begin{tabular}{llccc}
\hline Teaching method & Ability & N & Mean & Standard deviation \\
\hline Treatment & High & 32 & 85.23 & 3.668 \\
& Moderate & 66 & 67.27 & 7.854 \\
& Low & 32 & 55.00 & 4.666 \\
Control & Total & 130 & 68.67 & 12.448 \\
& High & 32 & 80.70 & 5.828 \\
& Moderate & 66 & 67.42 & 8.423 \\
\multirow{3}{*}{ Total } & Low & 32 & 52.19 & 7.261 \\
& Total & 130 & 66.94 & 12.557 \\
& High & 64 & 82.97 & 5.343 \\
& Moderate & 132 & 67.35 & 8.113 \\
& Low & 64 & 53.59 & 6.218 \\
& Total & 260 & 67.81 & 12.509 \\
\hline
\end{tabular}

Table 1 shows students achievement based on teaching methods and students abilities. Students in the treatment group showed that high ability students (mean $=85.23$ and $s d=3.668$ ) have higher achievement in the english language reading comprehension test than mediocre students (mean $=67.27$ and $s d=7.854$ ) and low ability students (mean $=$ 55.00 and $s d=4.666$ ). Whereas students in the control group showed that those with high ability (mean $=80.70$ and sd $=5.828$ ) have higher achievement in the English language reading comprehension test than students with moderate ability ( mean $=67.42$ and $s d=8.423$ ) and low ability students ( mean $=52.19$. and $s d=7.261$ ).

The overall achievement shows that students in the treatment group (mean $=68.67$ and $s d=12.448$ ) have higher achievement than students in the control group (mean $=66.94$ and $\mathrm{sd}=12.577$ ). Students' achievement in the English Language reading comprehension test based on teaching methods showed that high ability students (mean $=82.97$ and $s d=5.343$ ) have higher achievement than students with moderate ability (mean $=67.35$ and $s d p=8.113$ ) and low ability students (mean $=53.59$ and $s d=6.218$ ). The significant difference of students' achievement is described based on the two-way Anova analysis as shown in Table 2 below:

Table 2. Two-way Anova of reading comprehension achievement based on teaching method, between students who used the M-WebQuest and students who learned conventionally

\begin{tabular}{lccccc}
\hline Independent variables & Type III Sum of Squares & Df & Mean square & F & Sig. \\
\hline Teaching Method & 333.079 & 1 & 333.079 & 6.822 & 0.010 \\
Ability & 27669.040 & 2 & 13834.520 & 283.373 & 0.000 \\
Teaching Method * Ability & 261.124 & 2 & 130.562 & 2.674 & 0.071 \\
Standard error & 12400.509 & 254 & 48.821 & & \\
Total & 40525.385 & 259 & & & \\
\hline
\end{tabular}

Table 2 shows that there is a significant difference of students' achievement in the English Language reading comprehension test based on teaching methods with the $F$ value of $6.822=$ and sig $=0.000(p<0.05)$. The mean score shows that students who learned with the M-WQ have higher achievement than those who learned in the conventional way. This shows the nul hypothesis (Ho1) that there is no significant difference of students' achievement based on teaching method is rejected. In addition, there is a significant difference of students' achievement in the English Language reading comprehension test based on students' ability with the $F$ value $=283.373$ and $\operatorname{sig}=0.000(p<0.05)$.

The mean score shows that high ability students have higher achievement in the English Language reading 
comprehension test than those moderate and low ability students. However, the difference is not significant This shows the nul hypothesis (Ho2) that there is no significant difference of students' achievement based on students'ability is rejected. Due to the significant difference of achievement based on students' ability, the Scheffe Post Hoc analysis was then conducted to determine the details of the difference. Results of the analysis is shown in Table 3 below:

Table 3. Scheffe Post Hoc comparison of students achievement in the English Language Reading Comprehension Test based on students' ability

\begin{tabular}{llccc}
\hline (I) Ability & (J) Ability & mean difference (I-J) & Standard error & Sig. \\
\hline High & Moderate & 15.62 & 1.064 & 0.000 \\
\multirow{3}{*}{ Moderate } & Low & 29.37 & 1.235 & 0.000 \\
& High & -15.62 & 1.064 & 0.000 \\
\multirow{2}{*}{ Low } & Low & 13.75 & 1.064 & 0.000 \\
& High & -29.37 & 1.235 & 0.000 \\
& Moderate & -13.75 & 1.064 & 0.000 \\
\hline
\end{tabular}

Table 3 shows comparison of achievement that there is a significant difference of achievement between high ability students and mediocre students with the mean difference of mean= 15.62 and sig $=0.000(p<0.05)$.) There is also a significant difference of achievement between high ability students and low ability students with the mean difference of mean $=29.37$ and sig $=0.000(p<0.05)$.) High ability students have higher achievement in the English Language reading comprehension test than low ability students (mean $=67.42$ and $s d=8.423$ ) and low ability students (mean $=52.19$. and $\mathrm{sd}=7.261)$.

Thus, it was found that high ability students have higher achievement in the English Language reading comprehension test than low ability students. There is also a significant difference of achievement between mediocre students and low ability students with the mean difference of mean $=13.75$ and sig $=0.000(p<0.05)$.) So, it was found that mediocre students have higher achievement in the English Language reading comprehension test than low ability students.

The two-way Anova analysis shows that there is no significant difference of students' achievement in the English Language reading comprehension test based on teaching methods and different abilities, with the $\mathrm{F}$ value of $=2.674$ and sig $=0.071(p<0.05)$. This shows that the nul hypothesis $(\mathrm{Ho3})$ that there is no interaction between teaching methods and students' abilities is accepted.

7.2 Comparison of self-learning ability between students who used the M-WebQuest and students who learned conventionally based on students' ability

The two-way Anova analysis was done to determine any significant difference in self-learning competency between students who used the M-WebQuest and students who learned conventionally based on their ability. The result is shown in Table 4 below:

Table 4. Mean and standard deviation of self-learning competency between students who used the M-WebQuest and students who learned conventionally based on ability

\begin{tabular}{llccc}
\hline Teaching method & Ability & $\mathrm{N}$ & Mean & Standard Deviation \\
\hline Treatment & High & 32 & 4.33 & 0.149 \\
& Moderate & 66 & 4.33 & 0.132 \\
& Low & 32 & 4.27 & 0.129 \\
Control & Total & 130 & 4.31 & 0.137 \\
& High & 32 & 3.89 & 0.259 \\
& Moderate & 66 & 3.89 & 0.266 \\
\multirow{4}{*}{ Total } & Low & 32 & 3.89 & 0.317 \\
& Total & 130 & 3.89 & 0.276 \\
& High & 64 & 4.11 & 0.304 \\
& Moderate & 132 & 4.11 & 0.304 \\
& Low & 64 & 4.08 & 0.307 \\
& Total & 260 & 4.10 & 0.304 \\
\hline & & &
\end{tabular}


Table 4 shows students self-learning competency based on teaching methods and students abilities. Students in the treatment group showed that high ability students (mean $=4.33$ and $s d=0.149$ ) and mediocre students (mean $=4.33$ and $s d=0.132$ ) have higher self-learning competency than low ability students (mean $=4.27$ and $s d=0.129$ ). Whereas students in the control group showed that those with high ability (mean $=3.89$ and $s d=0.259$ ), mediocre students (mean $=3.89$ and $s d=0.276$ ) and low ability students (mean $=3.89$ and $s d=0.276$ ) have almost similar self-learning competency.

The overall achievement shows that students in the treatment group (mean $=4.31$ and $s d=0.137$ ) have higher self-learning competency than students in the control group (mean $=3.89$ and $s d=0.276$ ). Study based on ability, showed that high ability students (mean $=4.11$ and $s d=0.304$ ) have higher self-learning competency than students with moderate ability (mean $=4.11$ and $s d=0.304$ ) and low ability students (mean $=4.08$ and $s d=0.307$ ). The significant difference of students' self-learning competency is described based on the two-way Anova analysis is shown in Table 4.12 below:

Table 5. Two-way Anova Comparison of self-learning competency between students who used the M-WebQuest and students who learned conventionally based on students' ability

\begin{tabular}{lccccc}
\hline Independent variables & Type III Sum of Squares & Df & mean square & F & Sig. \\
\hline Teaching Method & 10.149 & 1 & 10.149 & 212.237 & 0.000 \\
Ability & 0.038 & 2 & 0.019 & 0.397 & 0.673 \\
Teaching Method * Ability & 0.039 & 2 & 0.020 & 0.413 & 0.662 \\
Standard error & 12.146 & 254 & 0.048 & & \\
Total & 23.897 & 259 & & & \\
\hline
\end{tabular}

Table 5 shows that there is a significant difference of students' self-learning competency based on teaching methods with the $F$ value of 212.237 and sig $=0.000(p<0.05)$. The mean score shows that students who learned with the M-WQ have higher self-learning competency than those who learned in the conventional way. This shows the nul hypothesis (Ho4) that there is no significant difference of students' self-learning competency based on teaching method is rejected. However, there is no significant difference of students' self-learning competency based on students' ability with the $F$ value $=0.397$ and $\operatorname{sig}=0.673(p<0.05)$.

The mean score shows that high ability students have higher self-learning competency than those moderate and low ability students. This means the nul hypothesis ( $\mathrm{Ho5})$ that there is no significant difference of students' self-learning competency based on ability is accepted. The two-way Anova analysis shows that there is no significant difference of self-learning competency between students who were taught using the M-WQ teaching method with students who were taught conventionally based on students different abilities, with the $F$ value of $=0.413$ and sig $=0.662(p>0.05)$. This means that the nul hypothesis (Ho6) that there is no significant interaction between teaching methods and students' abilities with self-learning competency is accepted.

\subsection{Correlation between self-learning competency and students' achievement in the English Language Reading Comprehension}

Pearson correlation Analysis was conducted to determine the relationship between self-learning competency and students' achievement in the English Language Reading Comprehension. Results of the analysis are shown in Table 6 below:

Table 6. Correlation between self-learning competency and students' achievement in the English Language Reading Comprehension

\begin{tabular}{cccc}
\hline \multirow{2}{*}{ Relationship } & \multicolumn{2}{c}{ Achievement in the English Language Reading Comprehension } & \multirow{2}{*}{ Interpretation } \\
\cline { 2 - 3 } & $\mathrm{r}$ & Sig. & \\
\hline Self-learning & 0.460 & 0.000 & Moderate/modest \\
\hline
\end{tabular}

There is a significant relationship between self-learning competency and students' achievement in the English Language reading comprehension test with the $r$ value of $=0.460$ and sig $=0.000(p<0.01)$. However the strenght is only moderate. This means the nul hypothesis $(\mathrm{Ho} 7)$ that there is no significant relationship between extrinsic motivation with 
students' achievement in the English Language reading comprehension is rejected.

\section{Discussion}

The two-way ANOVA analysis showed that there is a significant difference of students' achievement in the English Language reading comprehension based on teaching methods. Results of the analysis show that students who learned with the M-WQ have higher achievement in reading comprehension test than those in the control group who learned in the conventional way. Conclusion can be made that the use of M-WQ in teaching and learning has a significant influence to increase students' achivement in the English Language reading comprehension test among secondary school students.

The impact is obivious due to the fact that teaching with the help of M-WQ provides better and simpler concepts for students to memorise facts. This is because M-WQ has attractive features and it facilitates students to independently understand difficult concepts of the topics studied. Results of this study are in line with the findings of a study conducted by Almekhlafi (2006), which found that there is a significant difference of achievement between students who have computer assisted learning with those who continue to learn using conventional method. This has confirmed that technology-based of teaching English Language subject has positive effect on students' achievement of the subject.

There is a significant difference of achievement in the English language reading comprehension based on students' academic ability. This study has proven that high academic ability students have higher achievement than those mediocre and low ability students. Learning with M-WQ has incredible effect on students of diverse abilities, especially on students with high academic ability. There is no denial that M-WQ provides more interesting teaching activities to help English Language teachers executing thier lessons in the class. Attractive features of the M-WQ such as animations and pictures attract students and indeed it is another option of learning facility for students of diverse abilities to improve their achievement in the English Language reading comprehension.

Even though this study has found that high ability students have better acceptance on the use of M-WQ compared to mediocre students and low ability students. This is because a student who has high ability undoubtly can analyse text faster. This is in agreement with Skylar et. al (2007) who said that high ability students are more ready to use M-WQ in their learning process and they can adapt themselves with the new teaching method faster.

The difference of achievement and self-learning competency found in this study is common because students have different skills and knowledge on the use of technology. According to Azlina Mohd Kosnin and Lok Yian Lin (2010) a gap on students computer knowledge and skills is a hurdle for teacher to implement and manipulate technology in the teaching and learning, thus it is common when only students who know how to handle technology can increase their achievement.

Even though, M-WQ favours students with high ability but it is actually user-friendly to diversity of students regardless of students' skills and ability. Thus, M-WQ can be utilised by all level of students and suitable with any educational environment. This statement is in agreement with a statement by Halat (2007) that M-WQ is capable of providing appropriate activities for students of all school levels and it is also suitable with any educational environment.

The two-way Anova analysis shows that teaching methods used in this study have no significant difference of impact on students achievement in the English Language reading comprehension test based on students ability. This means that students of different ability who learned the English language subject using M-WQ and conventional method have the almost similar achievement. Conclusion can be made that students acceptance on the teaching is almost the samne. However, teaching with M-WQ is more effective and improves students achievement in the English Language reading comprehension test. This finding is supporting a finding by Clark (2006) who has found that technology is crucial in teaching and learning as it increases students' knowledge and understanding on the topic taught by the teacher.

This research has also found that there is a significant difference of self-learning competency among students based on teaching method. It is found that students who learned with the help of M-WQ have higher self-learning competency than students who learned conventionally. This is because M-WQ provides interesting activities which enable students to explore on their own based on the instruction given by the learning program. Students can work on the learning activity individually and will not face any difficulty as the learning concepts are explained to help students to digest the information easily. This finding is supporting a result found by a study conducted by Adeyemi (2012) that students have positive attitudes toward self-learning. This is due to the fact that the teaching method is suitable with students' level of understanding and it is also user friendly in helping students to upgrade their own self-learning capability.

This study has found that there is no significant difference of self-learning competency based on students level of 
ability. It is found that high ability and mediocre students have higher self-learning competency than low ability students. Hence, it can be said that students are capable to learn individually particularly high ability and mediocre students. The indicator of self-learning competency is when students are confident to generate the learning strategies individually and communicatively. And this statement is in agreement with a statement by Nanulu Chitashvili (2007). The aspects of selflearning are: self-confidence, individual exploration of learning strategies, students readiness to be responsible on their own learning; close relevancy with metacognitive strategies; planning, decision making, observation and assessment.

This study has found that there is no significant interaction between teaching method and students ability with selflearning competency. It is found that students who learned with the help of the M-WQ have higher self-learning competency regardless of ability compared to students who learned conventionally. Hence, conclusion can be made that there is no interaction among teaching methods, students' level of ability and self-learning competency. It is revealed by this study that when students learned with M-WQ, the level of their dependency on the teacher is lower that those students who learned conventionally. Students in the treatment group develop their own learning concept and congnitive. According to Macdougall (2008) self-learning is a type of learning characterised by a personality directed by oneself who is able to do self-taught without the help of a teacher or an instructor.

Pearson Correlation analysis has found that there is a significant relationship between self-learning with students' achievement in the English Language reading comprehension. This shows that the ability to learn independently (selflearning) can help students to increase their achievement. This is because self-learning competency directs students to acquire the skills to read English language material. Hence, it is concluded that the use of appropriate teaching method would help students to improve their achievement.

\section{Implication and Suggestions}

This study has found that the use of M-WQ increases students' achievement in their English language reading comprehension and self-learning. M-WQ provides the opportunity for students to actively explore and conduct activities individually without depending too much on the teacher. Reading activities in the M-WQ learning program develop students' learning skills especially in computer literacy. The use of M-WQ learning program also increases self-learning competency and reduces total dependence on the teacher. According to Alessi and Trollip (2001), computer-based of learning method helps students to learn individually by just following the clear instructions without total supervision by the subject teacher.

Teaching with the help of M-WQ has proven to be able to increase students' achievement in the English Language reading comprehension and self-learning competency. The use of M-WQ in teaching and learning process has also proven to be more effective compared to traditional and conventional teaching. According to

Abdul Razak and Jamaluddin (1998), most teachers agreed that computer is an effective teaching aid to increase students' understanding of certain concept effectively. Hence, English Language teachers should consider using M-WQ in the class. M-WQ learning program provides better time for teachers to develop their own teaching plan especially technology-based learning process. In addition, M-WQ requires teachers to be more creative in planning their teaching plan by making it suitable with computer application and syllabus of the subject. The lesson should be planned carefully to fully utilise the technology and at the same time to develop students' competency in self-learning. In conclusion, the teaching and learning computer program does not mean teachers can neglect their own responsibility in helping students to acquire the topic taught, but teachers have to guide and facilitate students to independently improve their own understanding on the topic learned.

\section{Closing}

This study has successfully adapted the use of M-WQ computer assited learning program and tested the effect of technology on students' achievement in the English Language reading comprehension and self-learning. This study contributes to the reading comprehension theories and adaptation of M-WQ to help students in reading comprehension, motivation and self-learning competency. This study has great implications on various parties particularly the students, teachers and the Indonesian Ministry of Education. Suggestions are given for better future studies. 


\section{References}

Almekhlafi, A.G. 2006. The effect of computer assisted language learning (CALL) on United Arab Emirates English as a Foreign Language (EFL) school students' achievement and attitude. ProQuest Education Journals pg.121.

Asmah Haji Omar. 2004. Research, Teaching and Language Inculcation. Kuala Lumpur: Dewan Bahasa dan Pustaka.

Azemi, A. 1997. "Developing An Active Learning Environment with Courseware Approach. "Proceedings of The 27th Frontier in Education Conference, Pittsburgh, PA, 1179-1184

Azizah Zain. 2010. Repetition reading technique in improving reading fluency and understanding among preschoolers. Proceedings of The $4^{\text {th }}$ International Conference on Teacher Education; Join Conference UPI \& UPSI Bandung, Indonesia.

Chew Fong Peng \& Abdul Jalil Othyman. 2008. The problems, factors and effects of neglecting Reading and Listening skills in the Malaysian secondary schools.SOSIOHUMANIKA, 1(1), 167-192.

Chuo, T. 2007. The effects of the WebQuest writing instruction: Program on EFL learners' writing performance, writing apprehension, and perception. TESL-EJ-Wenzao Ursuline College of Languages. Taiwan, 11(3), A-3.

Dodge, B. (1995). WebQuests: A technique for Internet-based learning. Distance Educator, 1(2), 10-13.

Halat, E. \& Jakubowski, E. (2001) Teaching Geometry Using WebQuest. 19th International Conference on Technology and Education: Tallahassee, Florida.

Ministry of Culture and Education. 2013. Training teachers in Implementing Curriculum, 2013. Jakarta: Department of Human resources Development of education and culture to determine education quality.

Little, D. 2000. Autonomy and autonomous learners. Byram, M. (ed.). Routledge Encyclopedia of Language Teaching and Learning. London: Routledge, 69-72.

Macdougall, M . 2008. Ten Tips For Promoting Autonomous Learning And Effective Engagement In The Teaching Of Statistics To Undergraduate Medical Students Involved In Short-Term Research Projects. Journal of Applied Quantitative Method. 3 (3): 223240.

Noerdin Soemantri. (2003). Methods to improve university students' competency in the English Language http://www.deliveri.org/guidelines/how/hm14/hm14_9i.htm

Norashikin Arif dan Zuhaidi Mukrim. 2005. Learning Process and its relationship with achievement in Mathematics.

http://kajianberasaskansekolah.files.wordpress.com/2008/02/kajianmatematik. pdf (14 September 2014).

Norazah Mohd Nordin \& Ngau Chai Hong. 2009. Developement and Evaluation of teaching and learning based on the Web-WebQuest for the ICT subject. Education Jurnal 34 (1): 111-129.

Raminah Hj. Sabran. 1993. Efficient Communication in the Malay language. Kuala Lumpur: Fajar Bakti.

Rasinski, T.V. 1990. Effect Of Repeat Reading and Listening-While-Reading on Reading Fluency. Journal Of Educational Research, 83(3), 147-150.

Richards, G. 2009. Book Review: Technology-mediated learning environment for young English learners. Educational Technology \& Society, 12(2), 334-336.

Rina Febritasari. 2010. A Study on the ability of the second year students of SMA Negeri 4 Pekanbaru in comprehending expository texts. Tesis Sarjana. Universitas Riau.

Rosnaini Mahmud \& Mohd Arif Hj. Ismail. 2010. Impact of Training and Experience in Using ICT on In-Service Teachers' Basic ICT Literacy. Malaysian Journal of Educational Technology, 10(2), 5-10.

Sahin, A. 2011. Effects of Jigsaw III Technique on Achievement in Written Expression. Asia Pacific Education Review. 12(30): $427-435$.

Simon, Alan E. 2005. The New Modus Operandi: Techno Tasking. www.asa.org /publications/saarticledetail. [6 Jun 2012].

Sinur Vera Afriana. 2012. Using three stay one stray strategy to increase the ability of the first year SMA Nurul Falah students in comprehending narrative text. Tesis Sarjana. Universitas Riau.

Skylar, A.A., Higgins, K, \& Boone, R. 2007. Strategies for Adapting WebQuests for Students With Learning Disabilities. Intervention in School and Clinic. 43(20), 20-28.

Wagman, J.C. 2005.The Effects of an Inquiry-Internet Research Project on Self-Efficacy, And Academic Autonomy in Heterogenously Grouped High School Latin I Students. Motivation. Thesis Ph.D. Capella University.

Walker, L.E. 1992. Battered women syndrome and self-defense. Symposium on Woman and the Law, Notre Dame Journal of Law, Ethics and Public Policy , 6(2), 321-334

Yuzar Muhammad. 2006. The influence of Jigsaw Technique on History results of Pekanbaru secondary schools students. Postgraduate Thesis. Padang University 
Printed for MCSER Publishing

by Gruppo Atena.net Srl

Via del Lavoro 22, 36040

Grisignano, VI, Italy

www.atena.net 